EASD

Procedia
EURODYN 2020

XI International Conference on Structural Dynamics M. Papadrakakis, M. Fragiadakis, C. Papadimitriou (eds.) Athens, Greece, 23-26 November 2020

\title{
FATIGUE LIFE ESTIMATION CONSIDERING THE QUASI- PERIODIC CROSS-WIND RESPONSE OF SLENDER STRUCTURES IN THE LOCK-IN RANGE
}

\author{
F. Lupi ${ }^{1,2}$, R. Höffer ${ }^{1}$, H.-J. Niemann ${ }^{2,1}$ \\ ${ }^{1}$ Ruhr-Universität Bochum \\ Universitaetsstraße 150, 44801 Bochum \\ e-mail: \{Francesca.lupi, Ruediger.Hoeffer, Hans-juergen.niemann\}@rub.de \\ ${ }^{2}$ Niemann\&Partner Engineering Consultants \\ Universitaetsstraße 142, 44799 Bochum
}

Keywords: Free-vibration wind tunnel tests, Fatigue, Rainflow Cycle Counting, Quasi-Periodicity

\begin{abstract}
The paper presents free-vibration wind tunnel tests on the aeroelastic model of a free-standing tower that shows vortex-induced vibrations in the lock-in range. Previous research by the authors focused on the investigation of the negative aerodynamic damping through forced-vibration tests. This knowledge allowed a realistic prediction for the maxima of the cross-wind oscillation amplitudes. In view of fatigue analysis, however, not only the maxima, rather a proper characterization of the cross-wind response is needed to determine the actual damage accumulation. Depending on the reduced wind velocity and the Scruton number of the vibrating structure, the experiments on the aeroelastic model in free vibrations show evidence of an intermittent - mathematically speaking quasi-periodic - behavior. It results from a beating effect between the natural oscillation frequency of the structure and the vortex shedding load, which may lock-in and lock-out in consequence of low frequency turbulence fluctuations. In addition, the frequency of the vortex shedding load along the height of the structure varies due to the varying mean velocity according to the wind profile and the varying Strouhal number. This exhibits smaller values close to the tip region. Outcomes of this investigation are the estimation of the negative aerodynamic damping through free-vibration wind tunnel tests and the estimation of the fatigue lifetime considering the quasi-periodic aeroelastic response through a rainflow fatigue load cycle counting.
\end{abstract}




\section{INTRODUCTION}

Slender structures subjected to vortex-induced vibrations (VIV) experience an aeroelastic interaction in the lock-in range. The negative aerodynamic damping, interpreted as energy transferred from the flow into the structure, is the governing parameter for the onset of selfinduced vibrations. However, available literature models still lack of a unified behavior of the aerodynamic damping as a function of the oscillation. This is also reflected in codified methods to design slender structures in view of cross-wind actions. This evidence applies firstly for the maxima of the oscillation amplitudes, i.e. the maxima of the structural stresses. Additionally, concerning the modelling of load processes for the analysis of fatigue strength, theoretical deficiencies cause even larger deviations between the prediction of fatigue life and its actual value.

A deeper knowledge about the non-linear behavior of the negative aerodynamic damping for a circular cylinder was gained by the authors from two-dimensional wind tunnel experiments in forced vibrations. The experiments were performed at the WISt Boundary Layer Wind Tunnel at Ruhr-Universität Bochum, Germany [10]. The experimental model of the aerodynamic damping developed in [10] was implemented in the spectral method originally proposed by Vickery\&Basu [14] and applied to 27 full-scale steel chimneys collected from literature. This novel spectral method, known also as "Damping Modified Spectral Method" (DMSM), allows the calculation of the largest oscillation of structures in the lock-in range [9]. Compared to other codified methods for structural analysis (e.g. [12], [13], [14]), DMSM provides a safe but more realistic prediction of the maxima of the cross-wind oscillation amplitudes. In view of fatigue analysis, however, not just one amplitude determines the damage, rather a proper characterization of the cross-wind response is needed to determine the actual damage accumulation.

Wind tunnel experiments on an aeroelastic model of a full-scale tower immersed in uniform, low-turbulent flow $\left(I_{V}=4,5 \%\right)$ are analyzed in this paper. The wind tunnel tests are performed at WISt Boundary Layer Wind Tunnel at Ruhr-Universität Bochum, Germany. First, the concept of the negative aerodynamic damping developed in [10] with the support of forced-vibration tests is now assessed in case of free-vibration experiments. Furthermore, the experiments on the aeroelastic model in free-vibrations demonstrate an intermittent - mathematically speaking quasi-periodic - behavior [11]. It results from a beating effect between the natural oscillation frequency of the structure and the vortex shedding load, which may lock-in and lock-out in consequence of low frequency turbulence fluctuations. Additionally, the frequency of the vortex shedding load along the height of the structure may vary due to varying mean velocity and varying Strouhal number, which exhibits smaller values close to the tip region.

For the purpose of fatigue calculations, current design models usually assume that the resonant vibration always occurs in the lock-in range with its largest value (see [5], [13]). This may lead, however, to an excessively conservative estimation of the fatigue damage.

In this paper, the contribution of the intermittent oscillations to fatigue life can be assessed from the aeroelastic measurements with the help of a rainflow load cycle counting. The load collectives that are determined from the time histories of the tower responses in the lock-in range for different Scruton numbers are then applied to a full-scale chimney sample, thereby allowing a realistic prediction of fatigue life. The result is then compared to the prediction of fatigue life by applying the standard procedure of the Eurocode [5]. 


\section{WIND TUNNEL EXPERIMENTS}

\subsection{Setup of free-vibration wind tunnel tests}

Free-vibration wind tunnel tests on a free-standing, aeroelastic model with circular crosssection are performed at WISt Boundary Layer Wind Tunnel at Ruhr-Universität Bochum, Germany. It is an open circuit wind tunnel with a test section of $1.8 \mathrm{~m}$ in width and $1.6 \mathrm{~m}$ in height (Figure 1). The tests are performed in uniform flow, with turbulence intensity Iv $=4.5 \%$.
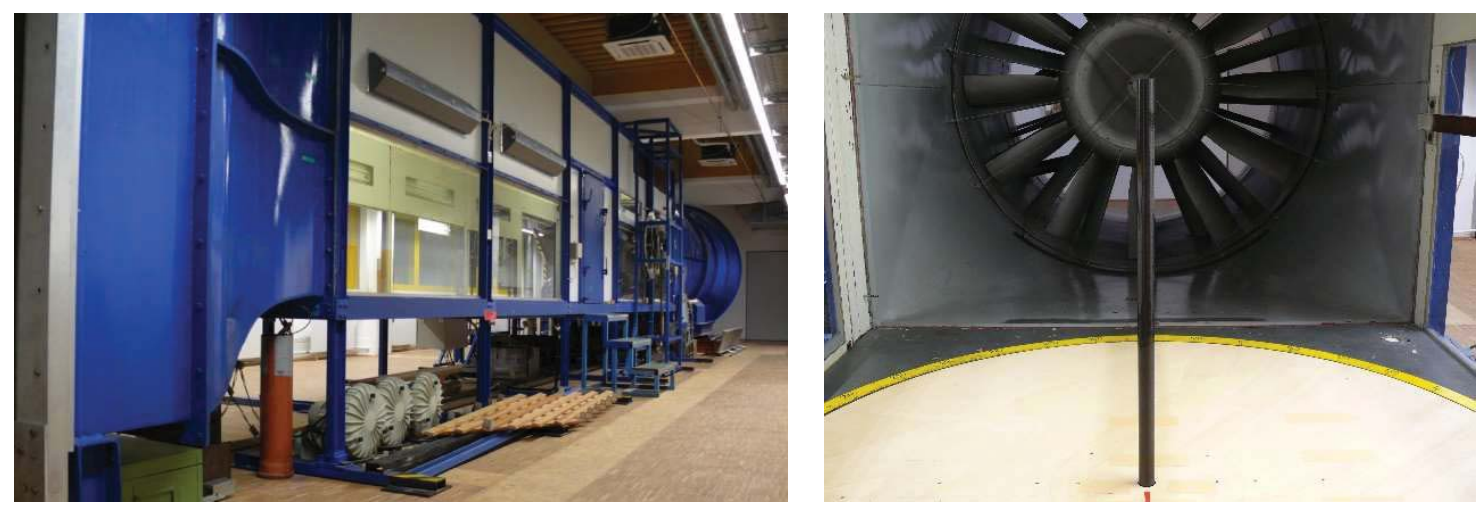

Figure 1: WISt Wind tunnel at Ruhr-Universitaet Bochum, Germany (left) and wind tunnel model (right)

The aeroelastic model for the free-vibration wind tunnel tests is a cantilever beam with circular cross-section (Figure 1). The model is fabricated with a carbon tube (external diameter 32 $\mathrm{mm}$ and internal diameter $29 \mathrm{~mm}$ ) that arises above the wind tunnel floor up to the height of $775 \mathrm{~mm}$ (measured from the wind tunnel floor). Below the wind tunnel, the carbon tube is connected to a steel bar (length $=210 \mathrm{~mm}$, diameter $15 \mathrm{~mm}$ ). The steel bar provides the necessary stiffness to the model and benefits from small damping dissipation. The steel bar is fixed to a force balance located at the model foot. Being the model surface smooth and the wind velocity below ca. $10 \mathrm{~m} / \mathrm{s}$, the Reynolds number of the investigation is subcritical $\left(\operatorname{Re}<2,1 \cdot 10^{4}\right)$.

The structural characteristics of the model that are relevant for the dynamic investigation such as the mode shape, the modal mass and the equivalent mass, are calculated through a finite element model of the wind tunnel prototype. It results the modal mass $\mathrm{M}_{1}=0.0630 \mathrm{~kg}$ and equivalent mass $\mathrm{m}_{\mathrm{eq}}=0.2286 \mathrm{~kg} / \mathrm{m}$. The finite element model also serves for a preliminary estimation of the natural frequencies and thus of the critical velocity of vortex resonance. The actual natural frequency of the model is measured through wind tunnel experiments in still air and in existence of wind. In addition, the snap-back tests in still air (free-decay tests) allow the estimation of structural damping. The behavior of the model in still air is described in the next section.

The reactions at the base of the model are measured by a 6-component force balance of the type K6D154 (ME-Meßsysteme). The measuring range is up to $200 \mathrm{~N}$ for the forces and up to $20 \mathrm{Nm}$ for moments. The force balance is composed by six independent sensors, which are equipped with strain gauges. The three forces along the axes $x, y$ and $z$ (named $F_{x}, F_{y}, F_{z}$ ) and the three bending moments around same axes $\left(M_{x}, M_{y}, M_{z}\right.$, respectively) can be calculated in time-domain through a calibration matrix applied to the volt signals measured by the sensors. The sampling frequency is set to $2000 \mathrm{~Hz}$. Every measurement lasts for 98,304 s.

The stiffness of the wind tunnel model is measured through static calibration tests with increasingly higher horizontal forces of known value applied at the top of the model. At the same time, the static displacement of the tip of the model is measured by a laser sensor. The stiffness of the model is linear. By means of the model flexibility, during dynamic tests the oscillation 
at the top of the model can be calculated from the forces or the bending moments measured at the base.

\subsection{Behavior of the model in still air}

Snap back tests are performed in still air to test the natural frequency of the model and its structural damping. The latter also includes the contribution of the still air damping. Figure 2 (left) shows a free-decay tests. The natural frequency in still air is about 22,3 Hz. The structural damping is evaluated from the oscillation amplitudes as logarithmic decrement:

$$
\delta_{s} \cong \frac{1}{m} \ln \left(\frac{A_{n}}{A_{n+m}}\right)
$$

The reversals considered for the evaluation of the structural damping are marked in blue in Figure 2 (left). The overall value of the damping, calculated considering the first and the last reversals in the free-decay time history, is $\delta_{\mathrm{s}}=0,018$. Additionally, a sensitivity study has been performed concerning the proper number $\mathrm{m}$ of cycles to be counted between two amplitudes in equation (1), in order to capture the non-linear behavior of the structural damping. Figure 2 (right) shows the behavior of the structural damping in case $\mathrm{m}=25$. The structural damping varies nonlinearly with the amplitude of oscillation between $\delta_{\mathrm{s}}=0,010$ and $\delta_{\mathrm{s}}=0,030$.
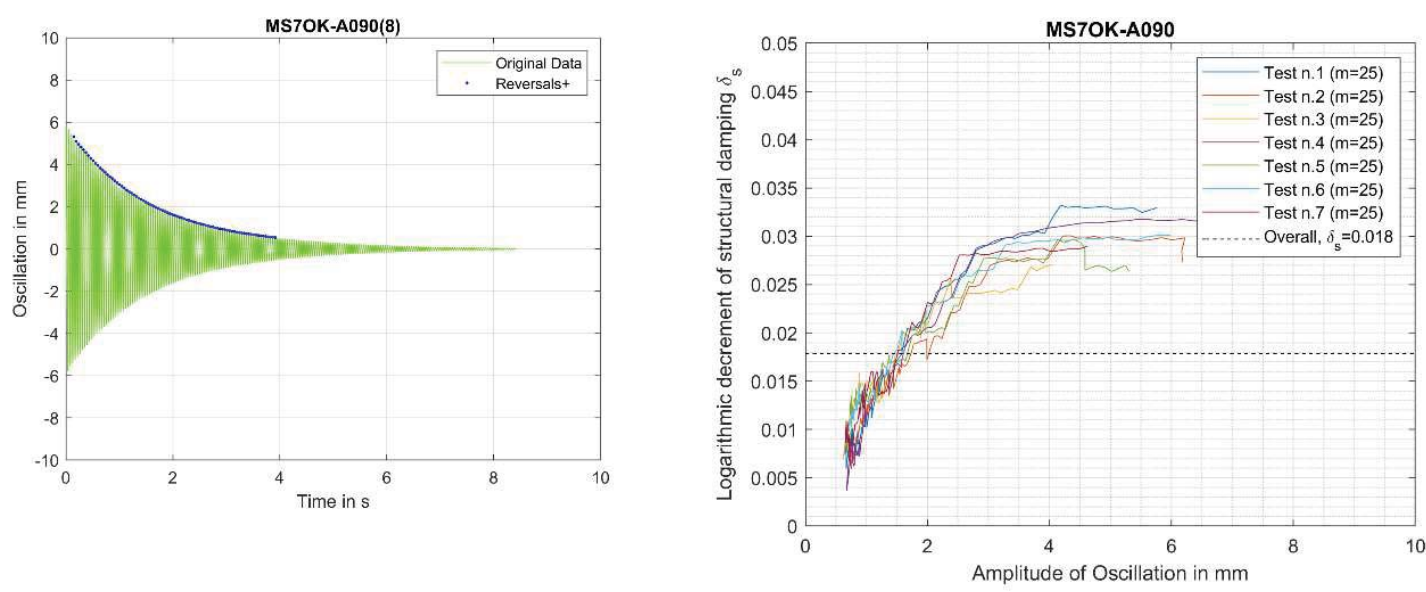

Figure 2: Snap back test and non-linear evaluation of the structural damping

\subsection{Resonant vibrations in the lock-in range}

The aeroelastic model of the tower is excited in the lock-in range for different wind velocities. Figure 3 shows the spectrum of the base force in the lift direction in case $\mathrm{V}_{\mathrm{H}} / \mathrm{V}_{\mathrm{cr}}=0,85 . \mathrm{V}_{\mathrm{H}}$ is the wind velocity referred to the height of the model. The natural frequency of the model remains substantially unchanged with respect to still air tests: $f_{1}=22,22 \mathrm{~Hz}$. The Strouhal number is $\mathrm{St}=0,203$ and this follows: $\mathrm{V}_{\mathrm{cr}}=3,50 \mathrm{~m} / \mathrm{s}$. 


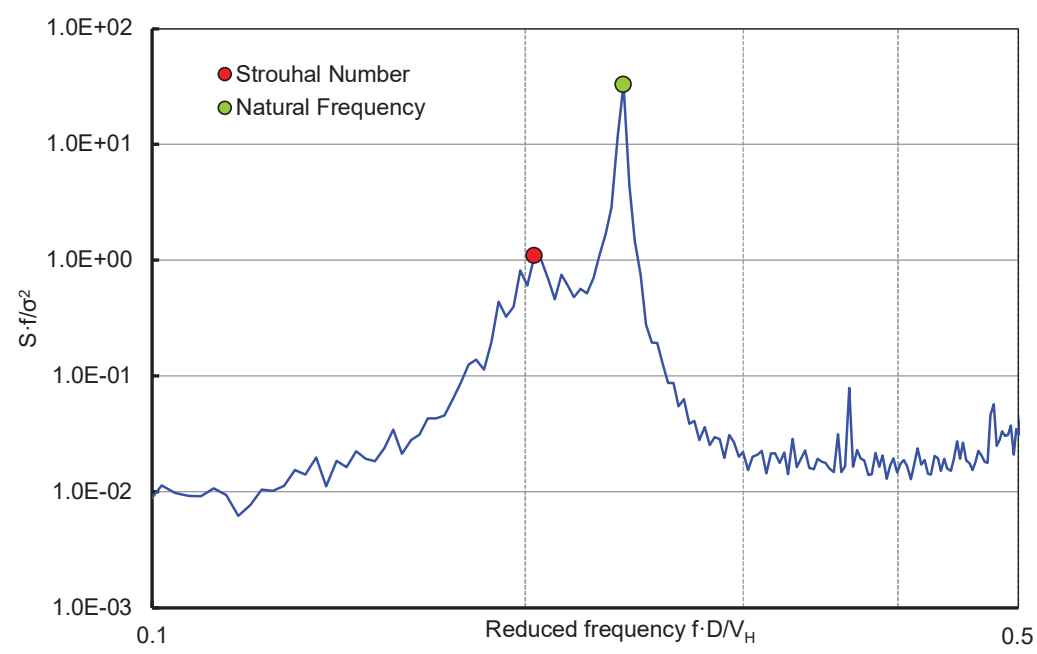

Figure 3: Spectrum of the base force in the lift direction, $V_{H}=2,99 \mathrm{~m} / \mathrm{s}, \mathrm{V}_{\mathrm{H}} / \mathrm{V}_{\mathrm{cr}}=0,85$

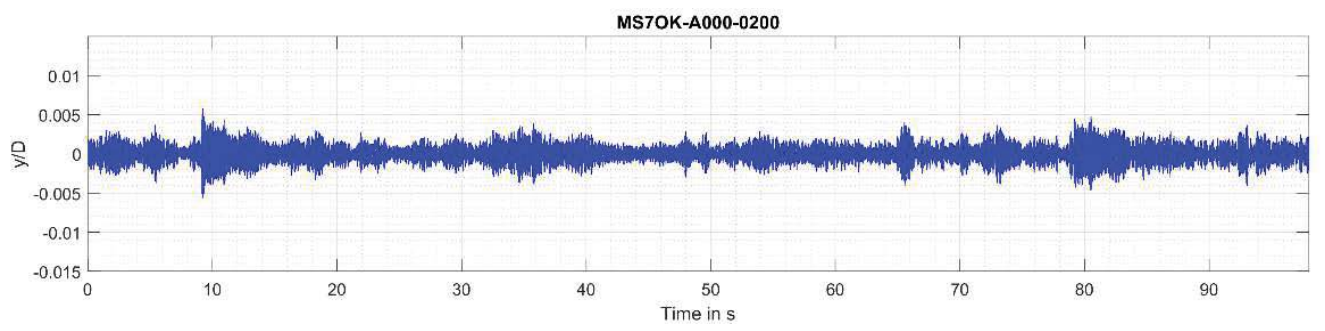

Figure 4: Time history of the response $\mathrm{y} / \mathrm{D}$ at $\mathrm{V}_{\mathrm{H}} / \mathrm{V}_{\mathrm{cr}}=0,85$

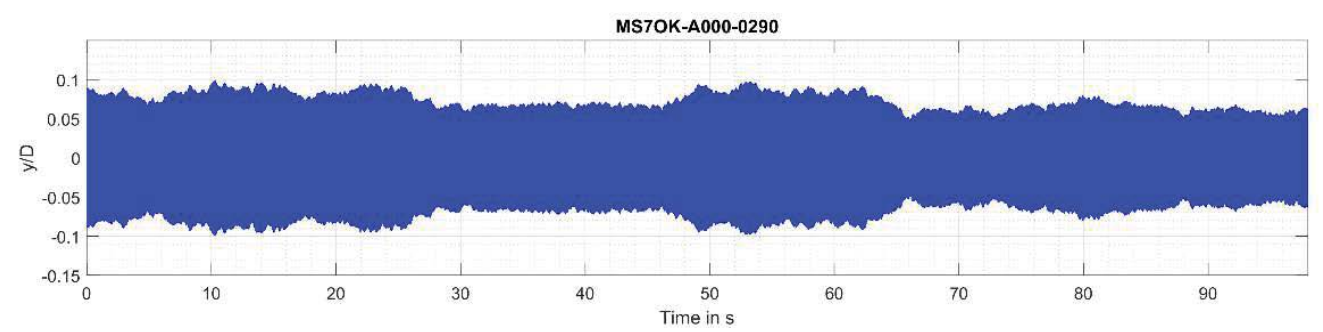

Figure 5: Time history of the response $\mathrm{y} / \mathrm{D}$ at $\mathrm{V}_{\mathrm{H}} / \mathrm{V}_{\mathrm{cr}}=1,13(\max )$

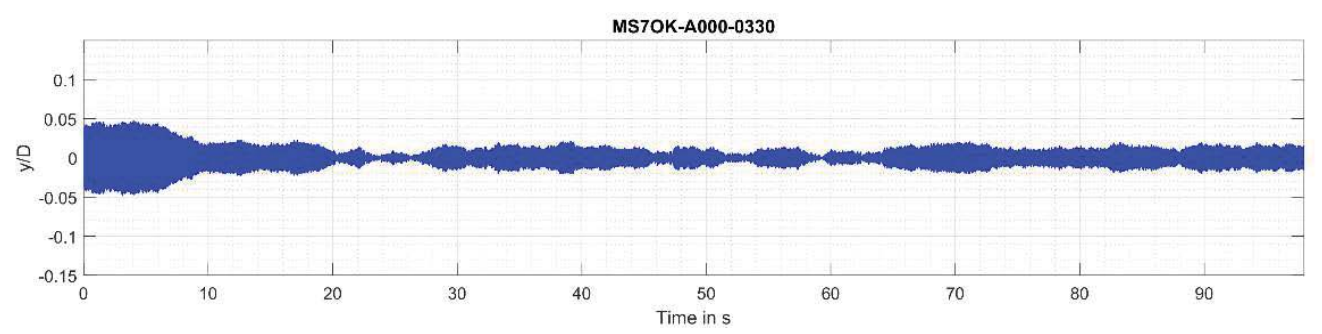

Figure 6: Time history of the response $\mathrm{y} / \mathrm{D}$ at $\mathrm{V}_{\mathrm{H}} / \mathrm{V}_{\mathrm{cr}}=1,25$

Figure 4, Figure 5 and Figure 6 show the time histories of the nondimensional response y/D for different velocities in the lock-in range. Because of the intermittency of the response, a question arises: is the response stationary, i.e. is the standard deviation a suitable parameter to describe the VIV response in the lock-in range? This issue is particularly important especially in view of the spectral analysis presented in the following sections, which considers the standard deviation of the response as governing parameter for the structural design. 


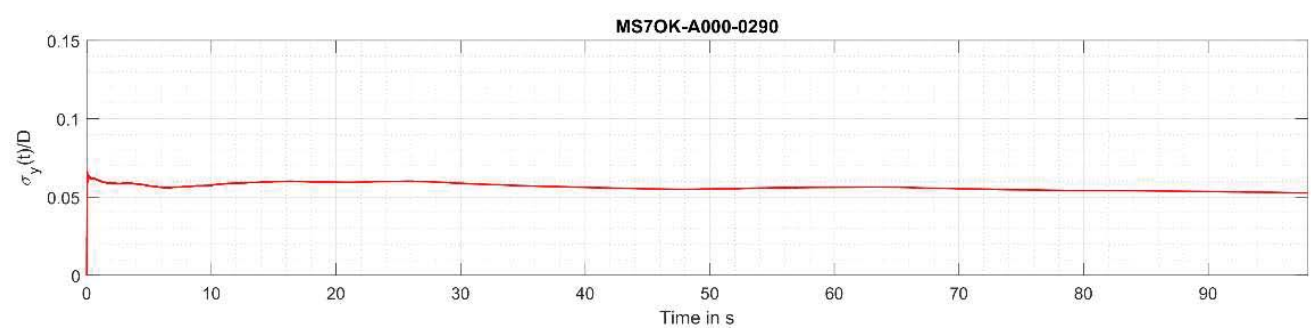

Figure 7: Convergence of the standard deviation of the response at $V_{H} / V_{\text {cr }}=1,13(\max )$

First, the convergence of standard deviation of the response for increasingly higher time intervals is investigated. Figure 7 shows that the recorded signal is long enough to ensure a robust estimation of standard deviation of the response.

Second, the stationarity of the response is investigated by dividing the time history in blocks of 10-min events in full-scale. The full-scale similarity considers a full-scale frequency $\mathrm{f}_{1, \mathrm{FS}}=$ $0,629 \mathrm{~Hz}$, as it will be explained later in Table 2 . Being the natural frequency in the wind tunnel experiments $\mathrm{f}_{1, \mathrm{WT}}=22,22 \mathrm{~Hz}$, it follows that the frequency scale is $\lambda_{\mathrm{F}}=35,33$ and the time scale is its inverse, i.e. $\lambda_{\mathrm{T}}=1 / \lambda_{\mathrm{F}}=0,028$. Therefore, 600 seconds in full-scale correspond to 16,98 seconds in the wind tunnel. Each of the recorded time histories includes five 10-min events in full-scale. For each event, the maximum amplitude and the standard deviation of the oscillation are calculated. Then, a statistical analysis of the maxima is performed to evaluate the mean value of the peak amplitudes among different events and the mean value of the standard deviations among different events. These two last parameters represent the statistical maximum and the statistical standard deviation, respectively, and they will be referred to in the following analysis. Their ratio allows calculating a statistically representative peak factor for the time history. Figure 8 shows the result for the case $\mathrm{V}_{\mathrm{H}} / \mathrm{V}_{\mathrm{cr}}=1,13$. In particular:

Mean value of maxima, $\mathrm{y}_{\max } / \mathrm{D}=0,0932$

Mean value of standard deviation, $\sigma_{\mathrm{y}} / \mathrm{D}=0.0536$

$$
\mathrm{k}_{\mathrm{p}}=\mathrm{y}_{\max } / \sigma_{\mathrm{y}}=1.74
$$
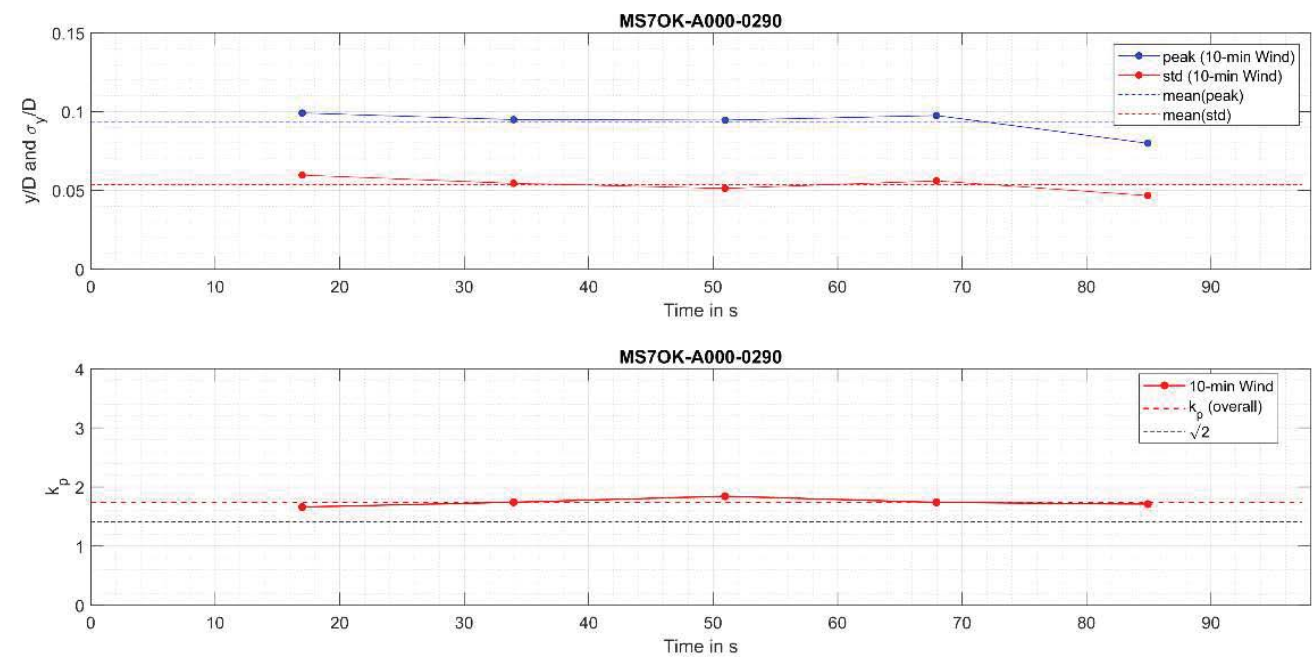

Figure 8: Analysis of peak amplitudes, standard deviations, peak factors $\mathrm{k}_{\mathrm{p}}$ for 10 -min events and for the overall time history $\left(\mathrm{V}_{\mathrm{H}} / \mathrm{V}_{\mathrm{cr}}=1,13(\max )\right)$ 


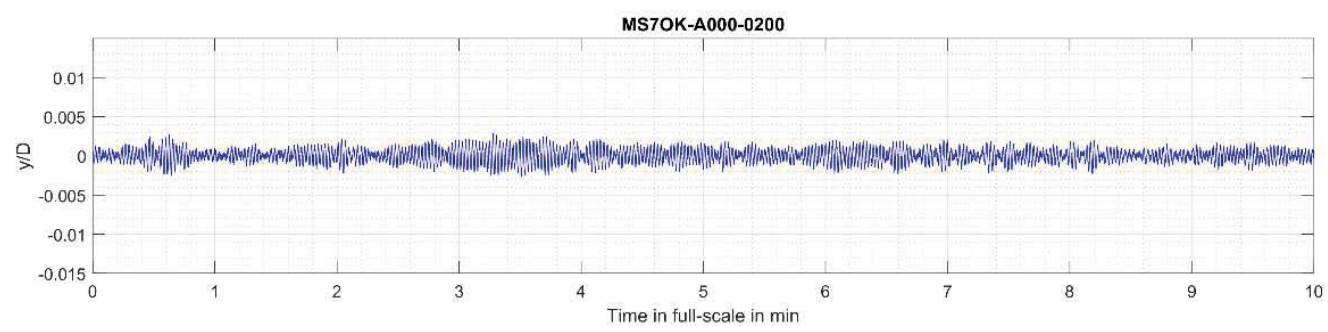

Figure 9: Time history of the response $y / D$ in 10-min full-scale interval at $V_{H} / V_{c r}=0,85$

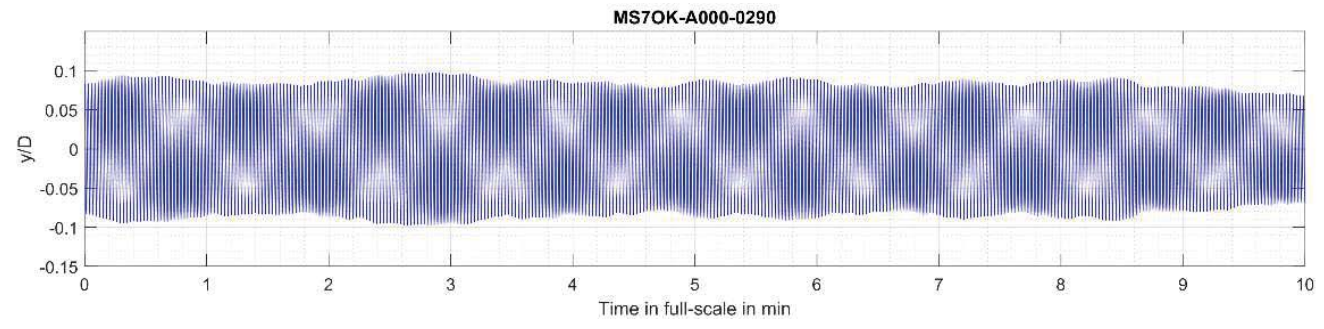

Figure 10: Time history of the response $\mathrm{y} / \mathrm{D}$ in 10 -min full-scale interval at $\mathrm{V}_{\mathrm{H}} / \mathrm{V}_{\mathrm{cr}}=1,13(\max )$

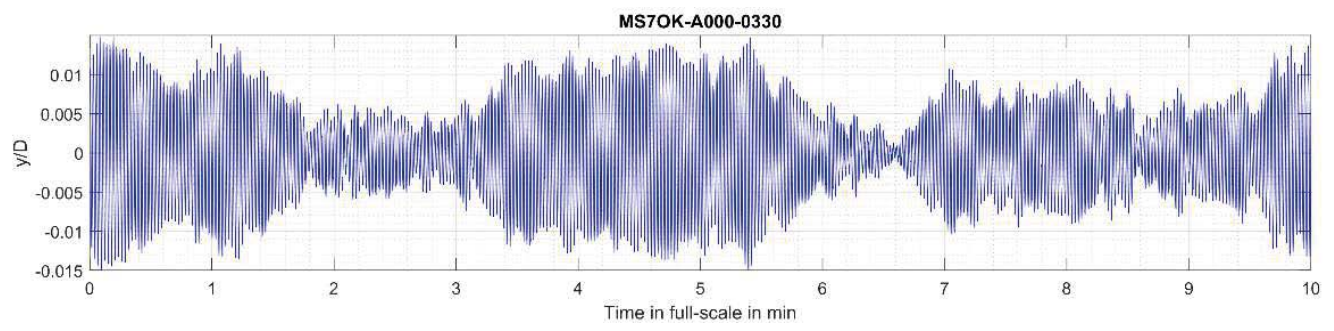

Figure 11: Time history of the response $\mathrm{y} / \mathrm{D}$ at $\mathrm{V}_{\mathrm{H}} / \mathrm{V}_{\mathrm{cr}}=1,25$

Furthermore, Figure 9, Figure 10 and Figure 11 show the time history of the response in a selected 10-min full-scale interval. For the sake of clarity, the y-axis is scaled 10 times in Figure 9 and Figure 11 with respect to Figure 10.

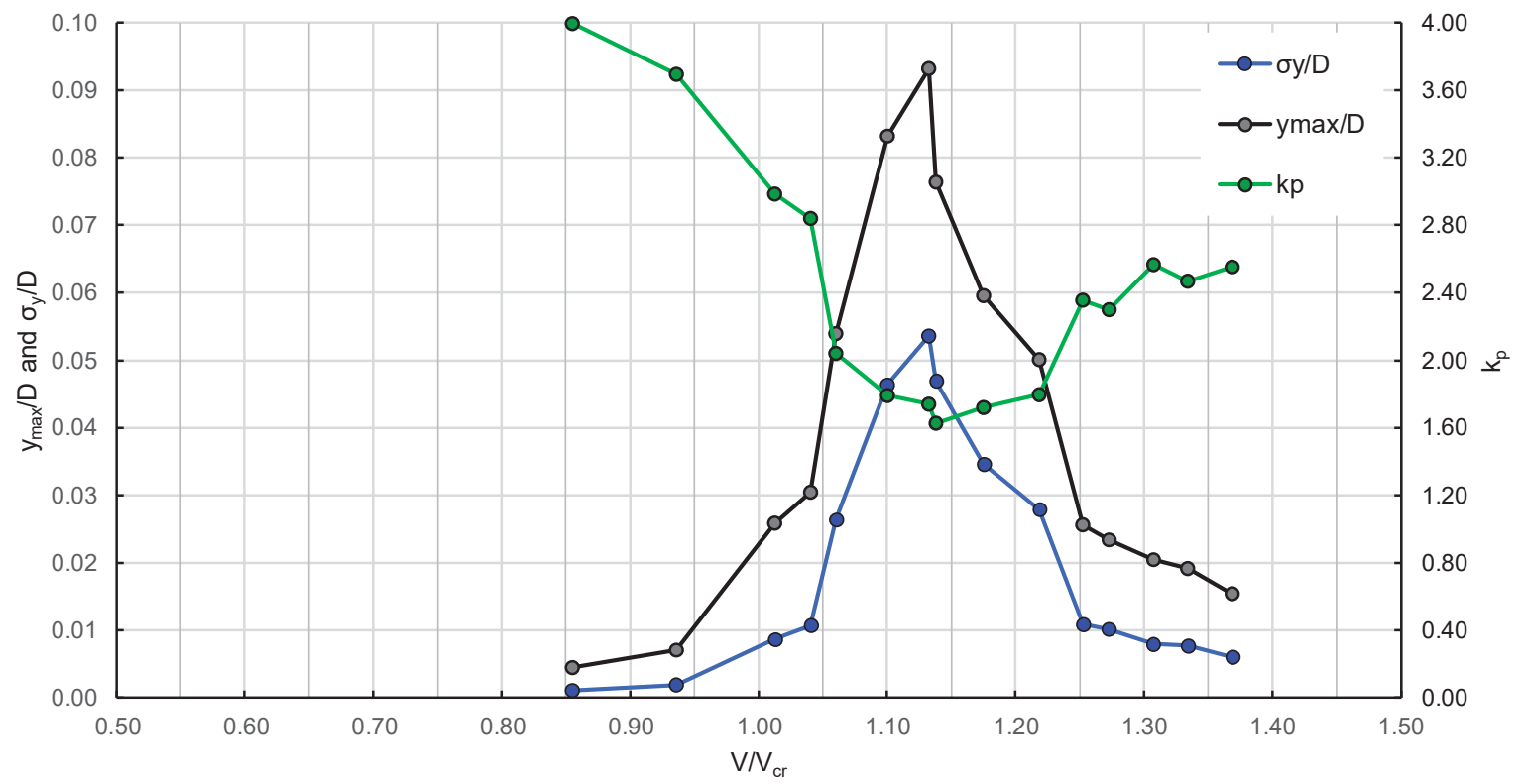

Figure 12: Statistical maxima of the oscillation, standard deviations and peak factors in the lock-in range 
Figure 12 shows the lock-in phenomenon. As it often occurs, the largest oscillation occurs for $\mathrm{V}>\mathrm{V}_{\mathrm{cr}}$. The right-hand side of the figure shows, instead, the distribution of the peak factors in the lock-in range. As expected, at the beginning and at the end of the lock-in range the stochastic behavior predominates and the peak factor increases. In full resonance, due to the predominant harmonic character, the peak factor is reduced. The ideal value $\sqrt{ } 2$ corresponds to the peak factor of a pure harmonic signal.

\section{ESTIMATION OF THE NEGATIVE AERODYNAMIC DAMPING FROM FREE- VIBRATION WIND TUNNEL TESTS}

Previous work of the authors allowed the measurement of negative aerodynamic damping $\mathrm{K}_{\mathrm{a}}$ in vortex-induced vibrations through forced vibration wind tunnel tests [10]. The behavior of the negative aerodynamic damping as a function of rms oscillation is described by the following curve:

$$
K_{a}=a \cdot e^{-b \cdot \frac{\sigma_{y}}{D}} \cdot\left(\frac{\sigma_{y}}{D}\right)^{c}
$$

with $\mathrm{a}=0,3464, \mathrm{~b}=5,808$ and $\mathrm{c}=0,3582$.

With regard to Equation (2), the largest oscillation in the lock-in range can be predicted by the following model, which originates from a modification of the Vickery\&Basu model [14]:

$$
\sigma_{\mathrm{y}}^{2}=\frac{\mathrm{S}_{\mathrm{L} 1}\left(\mathrm{f}_{\mathrm{n}}\right)}{\left(\omega_{1}^{2} \cdot \mathrm{M}_{1}\right)^{2}} \cdot \frac{\omega_{1}}{\frac{4}{\pi} \cdot\left(\delta_{S}+\delta_{a}\right)}=\frac{\mathrm{S}_{\mathrm{L} 1}\left(\mathrm{f}_{1}\right)}{\left(\omega_{1}^{2} \cdot \mathrm{M}_{1}\right)^{2}} \cdot \frac{\omega_{1}}{8 \cdot \frac{\rho \cdot d^{2}}{m_{e q}} \cdot\left(\frac{S c}{4 \pi}-K_{a}\right)}
$$

The background of equation (3) is explained in [9] and goes back to the evaluation of the resonant response to stochastic load in the first mode shape. The stochastic load is the vortex shedding load, which has a spectral density centered around the Strouhal frequency:

$$
\mathrm{S}_{\mathrm{L} 1}\left(\mathrm{f}_{1}\right) \cong 2 \lambda \cdot \int_{0}^{\mathrm{H}}\left(\frac{1}{2} \rho \mathrm{V}_{\mathrm{m}}(\mathrm{z})^{2}\right)^{2} \cdot \mathrm{D}(\mathrm{z})^{3} \cdot \frac{\sigma_{\mathrm{cL}}^{2}}{\sqrt{\pi} \cdot \mathrm{St}(\mathrm{z}) \cdot \frac{\mathrm{V}_{\mathrm{m}}(\mathrm{z})}{\mathrm{d}(\mathrm{z})} \cdot \mathrm{B}(\mathrm{z})} \cdot \exp \left(-\left(\frac{1-\frac{\mathrm{f}_{1}}{\mathrm{St}(\mathrm{z}) \cdot \frac{V_{\mathrm{m}}(\mathrm{z})}{\mathrm{d}(\mathrm{z})}}}{\mathrm{B}(\mathrm{z})}\right)^{2}\right) \cdot \Phi_{\mathrm{n}}(\mathrm{z})^{2} \cdot \mathrm{dz}
$$

By definition, the Vickery\&Basu model considers the load on the non-vibrating structure and includes all aeroelastic effects in the negative aerodynamic damping. Although this assumption may be questionable, it has little effect on the response prediction, as long as the response is predominantly governed by the motion-induced forces. This condition happens in the case of sufficiently small Scruton numbers, i.e. pronounced lock-in range. In this case, the major role in the response prediction is played by the accurate estimation of both structural and aerodynamic damping terms.

A further remark to equation (4), which follows from the assumption of the Vickery\&Basu model to consider load on the non-vibrating structure, is the absence of lock-in effect for $\mathrm{V} \neq$ $\mathrm{V}_{\mathrm{cr}}$, i.e. $\mathrm{f}_{\mathrm{s}}=\mathrm{St} \cdot \mathrm{V}_{\mathrm{m}} / \mathrm{d} \neq \mathrm{f}_{1}$. For example, the largest oscillation occurs for $\mathrm{V} / \mathrm{V}_{\mathrm{cr}}=1,13$ in the present experiment (see Figure 12). This is a typical behavior particularly for sufficiently small Scruton numbers. According to the equation (4), $\mathrm{S}_{\mathrm{L} 1}\left(\mathrm{f}_{1}\right)$ calculated for $\mathrm{V}_{\mathrm{m}}=1,10 \cdot \mathrm{V}_{\mathrm{cr}}$ is smaller than $\mathrm{S}_{\mathrm{L} 1}\left(\mathrm{f}_{1}\right)$ calculated for $\mathrm{V}_{\mathrm{m}}=\mathrm{V}_{\mathrm{cr}}$, due to the negative exponential function. Since the Strouhal law is violated in the lock-in range, it would be more reasonable not to apply any reduction to $\mathrm{S}_{\mathrm{L} 1}\left(\mathrm{f}_{1}\right)$ caused by the exponential term in the lock-in range, especially for $\mathrm{y}=\mathrm{y}_{\max }$. However, 
no further correction to the Vickery model is applied in this paper. Additional experimental evidence would be needed.

In present case, the nonlinear behavior of the structural damping needs to be considered, in order to ensure the most accurate estimation of the Scruton number which corresponds to the oscillation amplitude reached in lock-in. Referring to Figure 12 and considering the largest oscillation $\mathrm{y}_{\max } / \mathrm{D}=0,0932$ (i.e. $\mathrm{y}_{\max }=2,98 \mathrm{~mm}$ ), the corresponding structural damping is estimated as $\delta_{\mathrm{s}}=0,028$. The air density during the experiments is $1,16 \mathrm{~kg} / \mathrm{m}^{3}$. It follows Sc $=10,74$, being Sc defined as follows:

$$
\mathrm{Sc}=\frac{2 \cdot m_{e q} \cdot \delta_{s}}{\varrho \cdot D^{2}}
$$

Table 1 lists all the model parameters that are applied in this work to solve the equation (3). Unfortunately, some load parameters in equation (4), such as the rms value of the lift coefficient $\sigma_{\mathrm{cL}}$, the correlation length relative to the diameter $\lambda$ and the spectral bandwidth B, could not be measured during the experiments and therefore could only be estimated from literature and comparison with the Standard Codes.

\begin{tabular}{lllll}
\hline Parameter & Symbol & Unit & Value & Reference \\
\hline Model diameter & $\mathrm{D}$ & $\mathrm{m}$ & 0,032 & Wind tunnel model \\
Model height & $\mathrm{H}$ & $\mathrm{m}$ & 1,016 & Wind tunnel model \\
Model natural frequency & $\mathrm{f}_{1}$ & $\mathrm{~Hz}$ & 22,22 & Measured \\
Structural damping & $\delta_{\mathrm{s}}$ & - & 0,028 & Measured \\
Modal mass & $\mathrm{M}_{1}$ & $\mathrm{~kg}$ & 0.0630 & Calculated from FE model \\
Equivalent mass & $\mathrm{m}_{\mathrm{eq}}$ & $\mathrm{kg} / \mathrm{m}$ & 0.2286 & Calculated from FE model \\
$\int_{0}^{\mathrm{H}} \Phi_{\mathrm{n}}(\mathrm{z})^{2} \cdot \mathrm{dz}=\mathrm{M}_{1} / \mathrm{m}_{\mathrm{eq}}$ & - & - & 0,276 & Calculated from FE model \\
Scruton number & $\mathrm{Sc}$ & - & 10,74 & Calculated \\
Rms lift coefficient & $\sigma_{\mathrm{cL}}$ & - & 0,7 & EN 1991-1-4 [5] \\
Correlation length related to diameter & $\lambda$ & - & $1(\mathrm{i} . \mathrm{e} .1 \cdot \mathrm{d})$ & Estimated [2] \\
Spectral bandwidth & $\mathrm{B}$ & - & 0,145 & Estimated through 0,1 $+\mathrm{Iv}$ [2] \\
Strouhal number & $\mathrm{St}$ & - & 0,203 & Measured \\
Critical velocity & $\mathrm{V}_{\mathrm{cr}}$ & $\mathrm{m} / \mathrm{s}$ & 3,50 & Calculated from $\mathrm{V}_{\mathrm{cr}}=\mathrm{f}_{1} \cdot \mathrm{D} / \mathrm{St}$ \\
Wind velocity at y $=\mathrm{y}_{\max }$ (uniform pro- & $\mathrm{V}_{\mathrm{m}}$ & $\mathrm{m} / \mathrm{s}$ & 3,97 & Measured at y $=\mathrm{y}_{\mathrm{max}}$ \\
file) & $\mathrm{V}_{\mathrm{m}} / \mathrm{V}_{\mathrm{cr}}$ & - & & \\
Velocity ratio at y $=\mathrm{y}_{\max }$ & $\rho$ & $\mathrm{kg} / \mathrm{m}^{3}$ & 1,13 & Result \\
Air density & $\mathrm{y}$ & $\mathrm{mm}$ & 2,98 & Measured \\
Max amplitude of oscillation & $\sigma_{\mathrm{y}}$ & $\mathrm{mm}$ & 1,72 & Measured (Figure 12) \\
Rms of the oscillation at max & & & & Measured (Figure 12) \\
\hline
\end{tabular}

Table 1: List of model parameters

Considering all the parameters in Table 1, it is clear that the only unknown in equation (3) is the aerodynamic damping parameter $K_{a}$, which could be calculated. The result is $K_{a}=0,82$. Considering the $\mathrm{K}_{\mathrm{a}}$-curve proposed in [10] (equation (2)), the agreement is satisfying, as shown in Figure 13. On the other hand, the well-known Vickery curve

$$
K_{a}=K_{a 0}\left(1-\left(\frac{\sigma_{y}}{a_{L} \cdot D}\right)^{2}\right)
$$

would give $\mathrm{K}_{\mathrm{a}}=1,97$ at $\sigma_{\mathrm{y}} / \mathrm{D}=0.054$ by assuming $\mathrm{K}_{\mathrm{a} 0}=2$ and $\mathrm{a}_{\mathrm{L}}=0,4$ in accordance with [5] for the subcritical range of Reynolds number. 


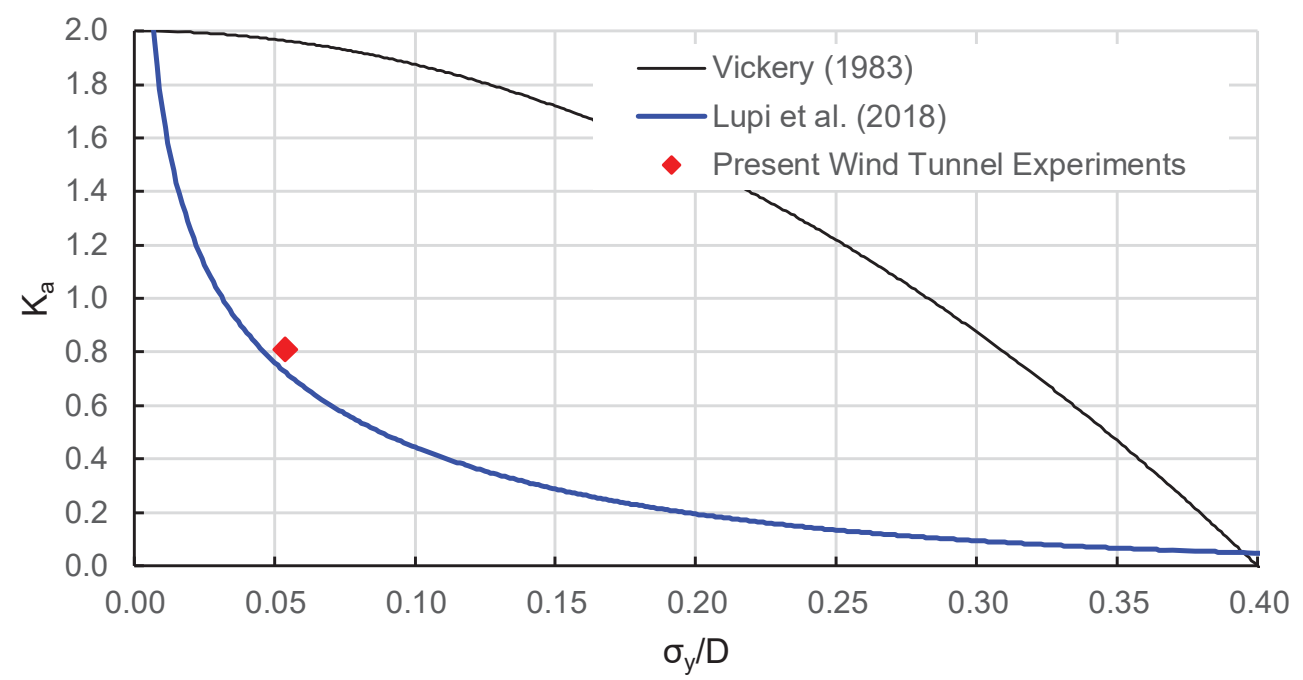

Figure 13: Estimation of negative aerodynamic damping parameter $\mathrm{K}_{\mathrm{a}}$ from free-vibration tests and comparison with literature

\section{PREDICTION OF FATIGUE LIFE}

\subsection{Case study}

For the purpose of fatigue life prediction, wind stresses caused by vortex excitation need to be calculated on a sample structure. For this purpose, the full-scale chimney in Skjern (Denmark), described in [8] and [3] and investigated by the authors in [9] is chosen as case study. The governing parameter is the similar Scruton number used. In details, the structural parameters of the full-scale chimney applied for this work are reported in Table 2.

\begin{tabular}{lllll}
\hline Parameter & Symbol & Unit & Value & Reference \\
\hline Tower diameter (constant) & $\mathrm{D}^{(\mathrm{FS})}$ & $\mathrm{m}$ & 1.1 & {$[8]$} \\
Tower height & $\mathrm{H}^{(\mathrm{FS})}$ & $\mathrm{m}$ & 45 & {$[8]$} \\
Tower natural frequency & $\mathrm{f}_{1}(\mathrm{FS})$ & $\mathrm{Hz}$ & 0,629 & {$[8]$} \\
Structural damping & $\delta_{\mathrm{s}}{ }^{(\mathrm{FS})}$ & - & 0,034 & {$[8]$} \\
Modal mass & $\mathrm{M}_{1}{ }^{(\mathrm{FS})}$ & $\mathrm{kg}$ & $2218 \mathrm{~kg}$ & $\mid$ Calculated from FE model \\
Equivalent mass & $\mathrm{m}_{\mathrm{eq}}{ }^{(\mathrm{FS})}$ & $\mathrm{kg} / \mathrm{m}$ & 246,4 & based on the mass distribution \\
$\int_{0}^{\mathrm{H}} \Phi_{\mathrm{n}}(\mathrm{z})^{2} \cdot \mathrm{dz}=\mathrm{M}_{1} / \mathrm{meq}$ & - & - & 9,00 & in [8] considering a parabolic mode shape \\
Scruton number & $-\mathrm{Sc}^{(\mathrm{FS})}$ & - & 11,078 & Calculated \\
\hline
\end{tabular}

Table 2: Full-scale chimney in Skjern (Denmark) [3], [8]

\subsection{Fatigue life estimation according to the Eurocode Method}

The Eurocode EN 1991-1-4 [5] proposes a method to calculate the fatigue life of a structure subjected to vortex excitation, which was originally developed in [13]. The method is based on the calculation of the number of load cycles around $\mathrm{V}=\mathrm{V}_{\mathrm{cr}}$ according to the Weibull distribution of the wind velocity. It further assumes that the vibration in the lock-in range is harmonic and its amplitude corresponds to the maximum resonant oscillation. The method is suitable for practical applications and generally provides safe results. The procedure is briefly described here and applied to the sample chimney in Table 2, in order to compare the results with a more sophisticated rainflow analysis for cycle counting, which is later applied to the wind tunnel measurements. 
The Weibull probability distribution of the wind velocity is characterized by two parameters, the shape parameter $\mathrm{k}$ and the scale parameter $\mathrm{A}$. The probability density function is:

$$
f(V)=\frac{k}{A} \cdot\left(\frac{V}{A}\right)^{k-1} \cdot e^{-\left(\frac{V}{A}\right)^{k}}
$$

The cumulative distribution function is the probability when the wind velocity $\mathrm{V}$ assumes a value less than or equal to $\mathrm{V}_{\mathrm{i}}$ :

$$
F(V)=P\left(V \leq V_{i}\right)=1-e^{-\left(\frac{V_{i}}{A}\right)^{k}}
$$

It follows that the probability when the wind velocity assumes values comprised between $\mathrm{V}_{1}$ and $\mathrm{V}_{2}$ is expressed as:

$$
P\left(V_{1} \leq V \leq V_{2}\right)=F\left(V_{2}\right)-F\left(V_{1}\right)=e^{-\left(\frac{V_{1}}{A}\right)^{k}}-e^{-\left(\frac{V_{2}}{A}\right)^{k}}
$$

In absence of wind statistics at the location of the structure, the Eurocode recommends:

- $\mathrm{k}=2$ (Rayleigh-Distribution)

- $\mathrm{A}=\sqrt{2} \cdot \mathrm{V}_{\text {mod, }}$, being $\mathrm{V}_{\text {mod }}$ the modal value of the Weibull probability distribution. The parameter " $A$ " can be taken as $20 \%$ of the mean wind velocity at the height of the cross-section where the vortex shedding occurs [5].

Assuming that the wind velocities $\mathrm{V}_{1}$ and $\mathrm{V}_{2}$ mark the beginning and the end of the lock-in range, respectively, the equation (8) describes the probability when the wind velocity excites the structure in the lock-in range. Considering the natural vibration frequency $f_{1}$, the number of load cycles in the lock-in range in the whole design lifetime of the structure $(\mathrm{T}=50$ years $=$ $3,1536 \cdot 10^{7} \cdot 50$ seconds) amounts to:

$$
N=3,1536 \cdot 10^{7} \cdot \mathrm{T} \cdot \mathrm{f}_{1} \cdot\left(e^{-\left(\frac{V_{1}}{A}\right)^{k}}-e^{-\left(\frac{V_{2}}{A}\right)^{k}}\right)
$$

For the purpose of simplicity, [13] proposes:

$$
e^{-\left(\frac{V_{1}}{A}\right)^{k}}-e^{-\left(\frac{V_{2}}{A}\right)^{k}}=f\left(V_{c r}\right) \cdot \Delta V=f\left(V_{c r}\right) \cdot \varepsilon_{0} \cdot V_{c r}=\frac{k}{A} \cdot\left(\frac{V_{c r}}{A}\right)^{k-1} \cdot e^{-\left(\frac{V_{c r}}{A}\right)^{k}} \cdot \varepsilon_{0} \cdot V_{c r}
$$

[13] recommends $\varepsilon_{0}=0,3$, meaning that the lock-in range extends for $0,3 \cdot V_{\text {cr }}$, (e.g. $V_{1}=$ $0,9 \cdot \mathrm{V}_{\mathrm{cr}}$ and $\mathrm{V}_{2}=1,2 \cdot \mathrm{V}_{\mathrm{cr}}$ ), which is often the case.

For the case under investigation, considering the natural frequency $\mathrm{f}_{1}=0,629 \mathrm{~Hz}$ (see Table 2 ), the scale parameter $A$ as $0,2 \cdot V_{m}(H)$, assuming the second terrain category and $\mathrm{vb}_{\mathrm{b}}=25 \mathrm{~m} / \mathrm{s}$ (see [5] and [6]), it results:

$$
A=0,2 \cdot V_{m}(H)=0,2 \cdot v_{b} \cdot\left(\frac{H^{(F S)}}{10}\right)^{0,16}=0,2 \cdot 25 \cdot\left(\frac{45}{10}\right)^{0,16}=6,36 \mathrm{~m} / \mathrm{s}
$$

The critical wind velocity $\mathrm{V}_{\text {cr }}$ is: 


$$
V_{c r}=\frac{f_{1} \cdot D^{(F S)}}{S t}=\frac{0,629 \cdot 1,1}{0.203}=3,41 \mathrm{~m} / \mathrm{s}
$$

Therefore:

$$
N=3,1536 \cdot 10^{7} \cdot \mathrm{T} \cdot \mathrm{f}_{1} \cdot \frac{k}{A} \cdot\left(\frac{V_{c r}}{A}\right)^{k-1} \cdot e^{-\left(\frac{V_{c r}}{A}\right)^{k}} \cdot \varepsilon_{0} \cdot V_{c r}=1,2823 \cdot 10^{8}
$$

The Eurocode Method assumes that the resonant vibrations of the structure in the lock-in range are harmonic with constant amplitude. Their amplitude corresponds to the maximum oscillation in the lock-in range. Using $\mathrm{y}_{\max } / \mathrm{d}$ value from the wind tunnel tests (Figure 12), it follows:

$$
y_{\max }^{(F S)}=\frac{y_{\max }}{d} \cdot D^{(F S)}=\frac{y_{\max }}{d} \cdot 1,1=0,0932 \cdot 1,1=0,103 \mathrm{~m}
$$

The wind stresses result from the following distribution of inertial forces along the height of the structure [5]:

$$
F_{w}(z)=m(z) \cdot\left(2 \cdot \pi \cdot f_{1}\right)^{2} \cdot \Phi_{1}(z) \cdot y_{\max }^{(F S)}
$$

For the purpose of this investigation, the bending moment at the base of the chimney is considered. Referring to the cross-section at the based described in [8] (diameter D $=1,1 \mathrm{~m}$ and wall thickness $t=0,016 \mathrm{~m}$ ), the maximum of the wind stress in resonance corresponds to $\sigma_{\max }$ $=13,91 \mathrm{~N} / \mathrm{mm}^{2}$, i.e. stress range $\Delta \sigma_{\max }=27,82 \mathrm{~N} / \mathrm{mm}^{2}$. The stress range corresponds to the difference between two extremes. The relationship between the maximum oscillation on top and the stress range at the base is as follows:

$$
\Delta \sigma=2 \cdot \frac{\int_{0}^{H} m(z) \cdot\left(2 \cdot \pi \cdot f_{1}\right)^{2} \cdot \Phi_{1}(z) \cdot z \cdot d z}{W} \cdot y_{\max }^{(F S)}
$$

The cumulative damage and the fatigue lifetime follow from the assumption of a detail category. Let us consider, for instance, the detail category 45 according to [7]. In this case, according to the Wöhler line, the number of load cycles $N_{R}$ to cause failure amounts to $1,2019^{*} 10^{7}$. From the previously calculated total number of load cycles of stress range $\Delta \sigma_{\max }$ during the required design life (equation (13)), it results:

$$
D_{d}=\frac{N}{N_{R}}=\frac{1,28.23 \cdot 10^{8}}{1,2019 \cdot 10^{7}}=10,67>1
$$

Being $D_{d}>1$, the structure will be damaged by fatigue during its lifetime of 50 years, i.e. after about 5 years. This result follows from the assumption that the vibration of the structure occurs in the lock-in range with constant amplitude equal to its maximum value. This assumption is particularly convenient for Code applications and is on the safe side. However, a more realistic fatigue lifetime may be estimated by considering the actual variability of the oscillation amplitude in the lock-in range, e.g. through rainflow counting. 


\subsection{Fatigue life estimation considering rainflow cycle counting}

The rainflow analysis is a method to count the number of load cycles and produce a stress range spectrum in case of time histories with varying amplitude. In this work, it is referred to the algorithm for rainflow counting that is described in ASTM E1049-85 [1].

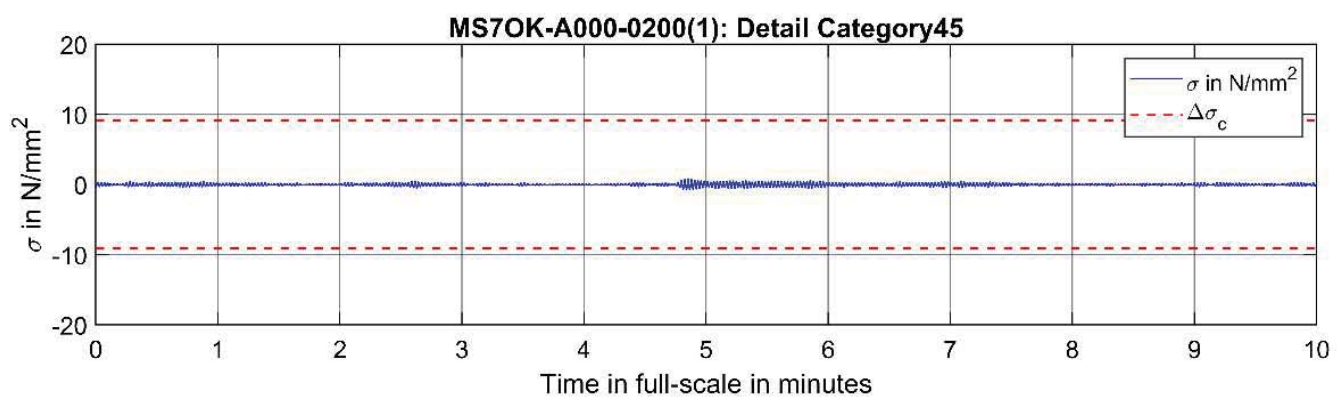

Figure 14: Time history of the stress response in 10-min full-scale interval at $\mathrm{V}_{\mathrm{H}} / \mathrm{V}_{\mathrm{cr}}=0,85$

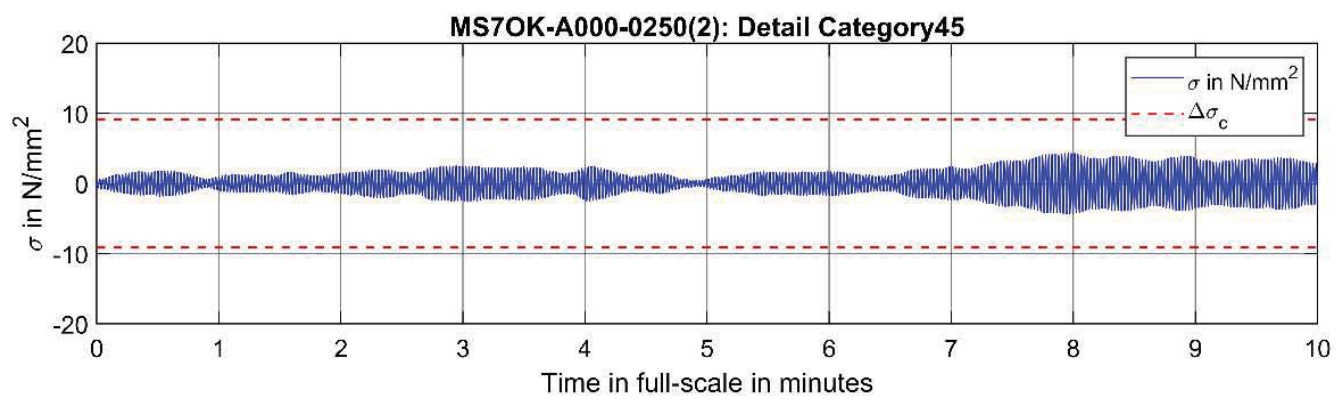

Figure 15: Time history of the stress response in 10-min full-scale interval at $\mathrm{V}_{\mathrm{H}} / \mathrm{V}_{\mathrm{cr}}=1,01$

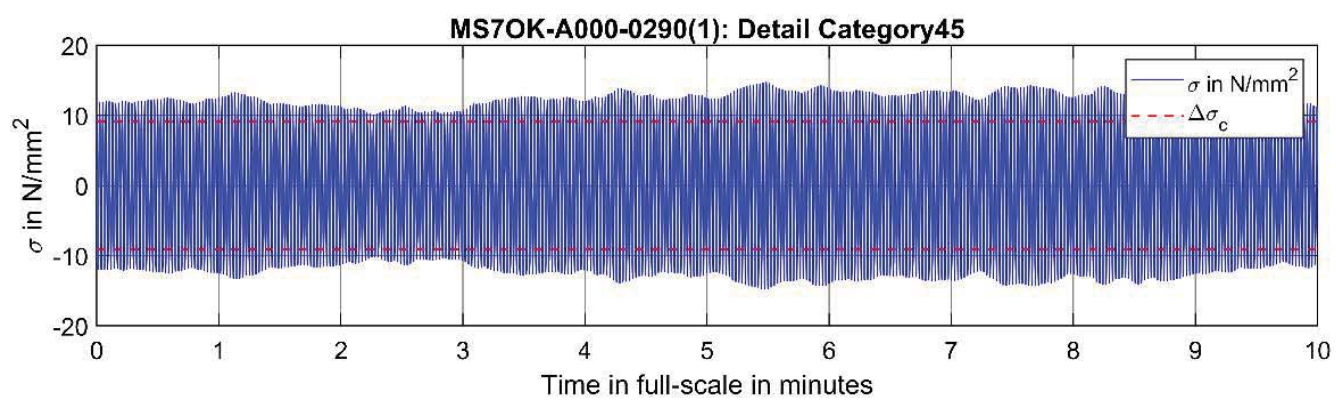

Figure 16: Time history of the stress response in 10-min full-scale interval at $\mathrm{V}_{\mathrm{H}} / \mathrm{V}_{\mathrm{cr}}=1,13$ (max). The dashed line indicates the cut-off stress for the Detail Category 45.

Figure 14, Figure 15, Figure 16 show some typical time histories of the stresses at the foot of the chimney in the lock-in range, which are calculated by integration of the inertial forces along the height according to the equation (15). The figures also plot $\Delta \sigma_{\mathrm{L}}$, i.e. the cut-off limit for the given detail category (in this case: $\mathrm{DC}=45$ ), i.e.:

$\Delta \sigma_{L}=\left(\frac{2}{5}\right)^{\frac{1}{3}} \cdot\left(\frac{5}{100}\right)^{\frac{1}{5}} \cdot D C=18,21 \mathrm{~N} / \mathrm{mm}^{2}$

For all stress ranges above the $\Delta \sigma_{\mathrm{L}}$ stress range, damage is accumulated. 


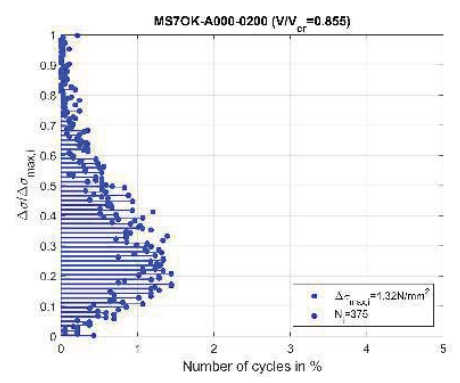

(a)

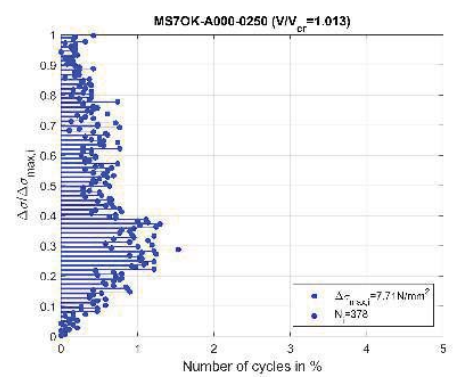

(b)

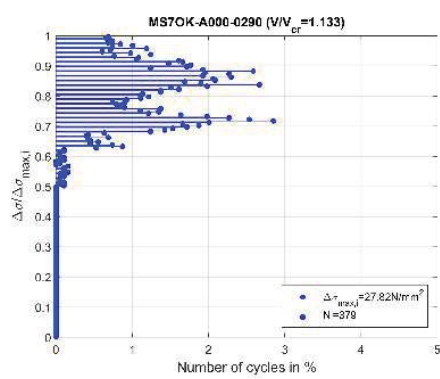

(c)

Figure 17: Stress collectives in the lock-in range by rainflow counting

Figure 17 describes the collectives, i.e. the stress range spectra, which correspond to the time histories in Figure 14, Figure 15, Figure 16, respectively. Figure 17 (a) shows a typical collective shortly before beginning of the lock-in range. In accordance with a stochastic signal, the number of cycles that correspond to the maxima of the oscillation is small compared to the number of cycles for smaller oscillation. A similar pattern is observed in Figure 17 (b). Figure 17 (c) - which corresponds to a fully resonant time history (see Figure 16), where the largest oscillation in the lock-in range is reached - indicates another behavior. Due to the predominant harmonic component, most of load cycles occur with the larger oscillations.

The calculation of the stress collectives from the experiments at different $V / \mathrm{V}_{\text {cr }}$ through rainflow cycle counting allows the calculation of actual cumulative damage in the structure. For each ratio $\mathrm{V} / \mathrm{V}_{\mathrm{cr}}$, a velocity class can be identified such that $\mathrm{V}_{1} \leq \mathrm{V} / \mathrm{V}_{\mathrm{cr}}<\mathrm{V}_{2}$. For each velocity class, depending on the Weibull distribution defined in equation (6), the probability when the wind velocity assumes values within the velocity class can be calculated (equation (8)). In this way, the number of load cycles for each velocity class can be calculated $\left(\mathrm{N}_{\mathrm{i}}\right)$ according to the equation (9).

Table 3 shows the calculation of the cumulative damage by considering largest stress range $\Delta \sigma_{\max , \mathrm{i}}$ for each velocity class and attributing it to the number of cycles $\mathrm{N}_{\mathrm{i}}$. The calculation assumes that the vibration in each velocity class is harmonic and its amplitude corresponds to $y_{m a x, i} / D$ in the lock-in curve shown in Figure 12. The rainflow counting is not considered in this calculation. The cumulative damage then results:

$$
\mathrm{D}_{\mathrm{d}}=1,752>1 \text { (considering the lock-in range but without rainflow counting) }
$$

It means a reduction of the fatigue lifetime to about 28,5 years. On the other hand, if the intermittent behavior is considered through rainflow analysis and each stress collective such as those in Figure 17 is considered for each velocity class, the cumulative damage results smaller than 1 , i.e. the structure will not be damaged by fatigue during the whole lifetime ( 50 years):

$$
\mathrm{D}_{\mathrm{d}}=0,659<1 \text { (considering rainflow counting) }
$$

Finally, given the cumulative damage calculated through rainflow analysis, the equivalent stress ranges which correspond to the cumulative damage can be calculated for each velocity class (Table 5). From that, equivalent oscillation amplitudes and equivalent peak factors for fatigue analysis in the lock-in range are developed. Figure 18 shows the peak factors for the ultimate limit state (already shown in Figure 12), which provide the maxima in the lock-in range. The peak factors for fatigue analysis, which provide equivalent stresses that give the same cumulative damage as the rainflow analysis, are also shown in the figure. 


\begin{tabular}{cccccccccc}
\hline $\begin{array}{c}\text { Veloc- } \\
\text { ity clas- } \\
\text { ses }\end{array}$ & $\begin{array}{c}\mathrm{V}_{\mathrm{a}} \\
{[\mathrm{m} / \mathrm{s}]}\end{array}$ & $\begin{array}{c}\mathrm{V}_{\mathrm{b}} \\
{[\mathrm{m} / \mathrm{s}]}\end{array}$ & $\begin{array}{c}\mathrm{V}_{\mathrm{i}} \\
{[\mathrm{m} / \mathrm{s}]}\end{array}$ & $\mathrm{V}_{\mathrm{i}} / \mathrm{V}_{\mathrm{cr}}$ & $\begin{array}{c}\mathrm{N}_{\mathrm{i}}=\text { Number } \\
\text { of load cycles } \\
\text { (Weibull) }\end{array}$ & $\begin{array}{c}\mathrm{y}_{\max , \mathrm{i}} / \mathrm{D} \\
{[-]}\end{array}$ & $\begin{array}{c}\Delta \sigma_{\max , \mathrm{i}}= \\
\text { stress } \\
\text { range } \\
{\left[\mathrm{N} / \mathrm{mm}^{2}\right]}\end{array}$ & $\begin{array}{c}\mathrm{N}_{\mathrm{Ri}}=\text { Number } \\
\text { of load cycles } \\
\text { to failure }\end{array}$ & $\begin{array}{c}\mathrm{D}_{\mathrm{d}}=\mathrm{N}_{\mathrm{i}} / \mathrm{N}_{\mathrm{Ri}}= \\
\text { Cumulative } \\
\text { Damage }\end{array}$ \\
\hline 1 & 2.78 & 3.05 & 2.91 & 0.855 & $3.20 \mathrm{E}+07$ & 0.004 & 1.325 & Inf & 0.000 \\
2 & 3.05 & 3.32 & 3.19 & 0.936 & $3.27 \mathrm{E}+07$ & 0.007 & 2.117 & Inf & 0.000 \\
3 & 3.32 & 3.50 & 3.45 & 1.013 & $2.24 \mathrm{E}+07$ & 0.026 & 7.705 & Inf & 0.000 \\
4 & 3.50 & 3.58 & 3.55 & 1.041 & $1.04 \mathrm{E}+07$ & 0.030 & 9.088 & Inf & 0.000 \\
5 & 3.58 & 3.68 & 3.62 & 1.061 & $1.31 \mathrm{E}+07$ & 0.054 & 16.114 & Inf & 0.000 \\
6 & 3.68 & 3.81 & 3.75 & 1.101 & $1.59 \mathrm{E}+07$ & 0.083 & 24.832 & $2.12 \mathrm{E}+07$ & 0.751 \\
7 & 3.81 & 3.87 & 3.86 & 1.133 & $8.47 \mathrm{E}+06$ & 0.093 & 27.822 & $1.20 \mathrm{E}+07$ & 0.705 \\
8 & 3.87 & 3.95 & 3.88 & 1.139 & $9.63 \mathrm{E}+06$ & 0.076 & 22.805 & $3.25 \mathrm{E}+07$ & 0.296 \\
9 & 3.95 & 4.08 & 4.01 & 1.176 & $1.80 \mathrm{E}+07$ & 0.060 & 17.786 & Inf & 0.000 \\
10 & 4.08 & 4.21 & 4.15 & 1.219 & $1.74 \mathrm{E}+07$ & 0.050 & 14.959 & Inf & 0.000 \\
11 & 4.21 & 4.30 & 4.27 & 1.253 & $1.23 \mathrm{E}+07$ & 0.026 & 7.665 & Inf & 0.000 \\
12 & 4.30 & 4.40 & 4.34 & 1.273 & $1.25 \mathrm{E}+07$ & 0.023 & 6.966 & Inf & 0.000 \\
13 & 4.40 & 4.50 & 4.46 & 1.308 & $1.41 \mathrm{E}+07$ & 0.020 & 6.107 & Inf & 0.000 \\
14 & 4.50 & 4.61 & 4.55 & 1.335 & $1.39 \mathrm{E}+07$ & 0.019 & 5.703 & Inf & 0.000 \\
15 & 4.61 & 4.72 & 4.67 & 1.369 & $1.55 \mathrm{E}+07$ & 0.015 & 4.595 & Inf & 0.000 \\
\hline Sum & & & & & $2.485 \mathrm{E}+08$ & & & & $\mathbf{1 . 7 5 2}$ \\
\hline
\end{tabular}

Table 3: Cumulative damage in the lock-in range without rainflow counting

\begin{tabular}{cccccccc}
\hline $\begin{array}{c}\text { Veloc- } \\
\text { ity clas- } \\
\text { ses }\end{array}$ & $\begin{array}{c}\mathrm{V}_{\mathrm{a}} \\
{[\mathrm{m} / \mathrm{s}]}\end{array}$ & $\begin{array}{c}\mathrm{V}_{\mathrm{b}} \\
{[\mathrm{m} / \mathrm{s}]}\end{array}$ & $\begin{array}{c}\mathrm{V}_{\mathrm{i}} \\
{[\mathrm{m} / \mathrm{s}]}\end{array}$ & $\mathrm{V}_{\mathrm{i}} / \mathrm{V}_{\mathrm{cr}}$ & $\begin{array}{c}\mathrm{N}_{\mathrm{i}}=\text { Number of } \\
\text { load cycles } \\
\text { (Weibull) }\end{array}$ & $\begin{array}{c}\mathrm{N}_{\mathrm{Ri}}=\text { Number of load } \\
\text { cycles to failure }=\mathrm{N}_{\mathrm{i}} / \mathrm{D}_{\mathrm{d}}\end{array}$ & $\begin{array}{c}\mathrm{D}_{\mathrm{d}} \text { = Cumulative dam- } \\
\text { age through Rainflow }\end{array}$ \\
\hline 1 & 2.78 & 3.05 & 2.91 & 0.855 & $3.20 \mathrm{E}+07$ & Inf & 0.000 \\
2 & 3.05 & 3.32 & 3.19 & 0.936 & $3.27 \mathrm{E}+07$ & Inf & 0.000 \\
3 & 3.32 & 3.50 & 3.45 & 1.013 & $2.24 \mathrm{E}+07$ & Inf & 0.000 \\
4 & 3.50 & 3.58 & 3.55 & 1.041 & $1.04 \mathrm{E}+07$ & Inf & 0.000 \\
5 & 3.58 & 3.68 & 3.62 & 1.061 & $1.31 \mathrm{E}+07$ & Inf & 0.234 \\
6 & 3.68 & 3.81 & 3.75 & 1.101 & $1.59 \mathrm{E}+07$ & $6.80 \mathrm{E}+07$ & 0.279 \\
7 & 3.81 & 3.87 & 3.86 & 1.133 & $8.47 \mathrm{E}+06$ & $3.03 \mathrm{E}+07$ & 0.145 \\
8 & 3.87 & 3.95 & 3.88 & 1.139 & $9.63 \mathrm{E}+06$ & $6.64 \mathrm{E}+07$ & 0.000 \\
9 & 3.95 & 4.08 & 4.01 & 1.176 & $1.80 \mathrm{E}+07$ & Inf & 0.000 \\
10 & 4.08 & 4.21 & 4.15 & 1.219 & $1.74 \mathrm{E}+07$ & Inf & 0.000 \\
11 & 4.21 & 4.30 & 4.27 & 1.253 & $1.23 \mathrm{E}+07$ & Inf & 0.000 \\
12 & 4.30 & 4.40 & 4.34 & 1.273 & $1.25 \mathrm{E}+07$ & Inf & 0.000 \\
13 & 4.40 & 4.50 & 4.46 & 1.308 & $1.41 \mathrm{E}+07$ & Inf & 0.000 \\
14 & 4.50 & 4.61 & 4.55 & 1.335 & $1.39 \mathrm{E}+07$ & Inf & $\mathbf{0 . 6 5 9}$ \\
\hline 15 & 4.61 & 4.72 & 4.67 & 1.369 & $1.55 \mathrm{E}+07$ & & \\
\hline Sum & & & & & $2.48 \mathrm{E}+08$ & & \\
\hline
\end{tabular}

Table 4: Cumulative damage in the lock-in range by rainflow counting 


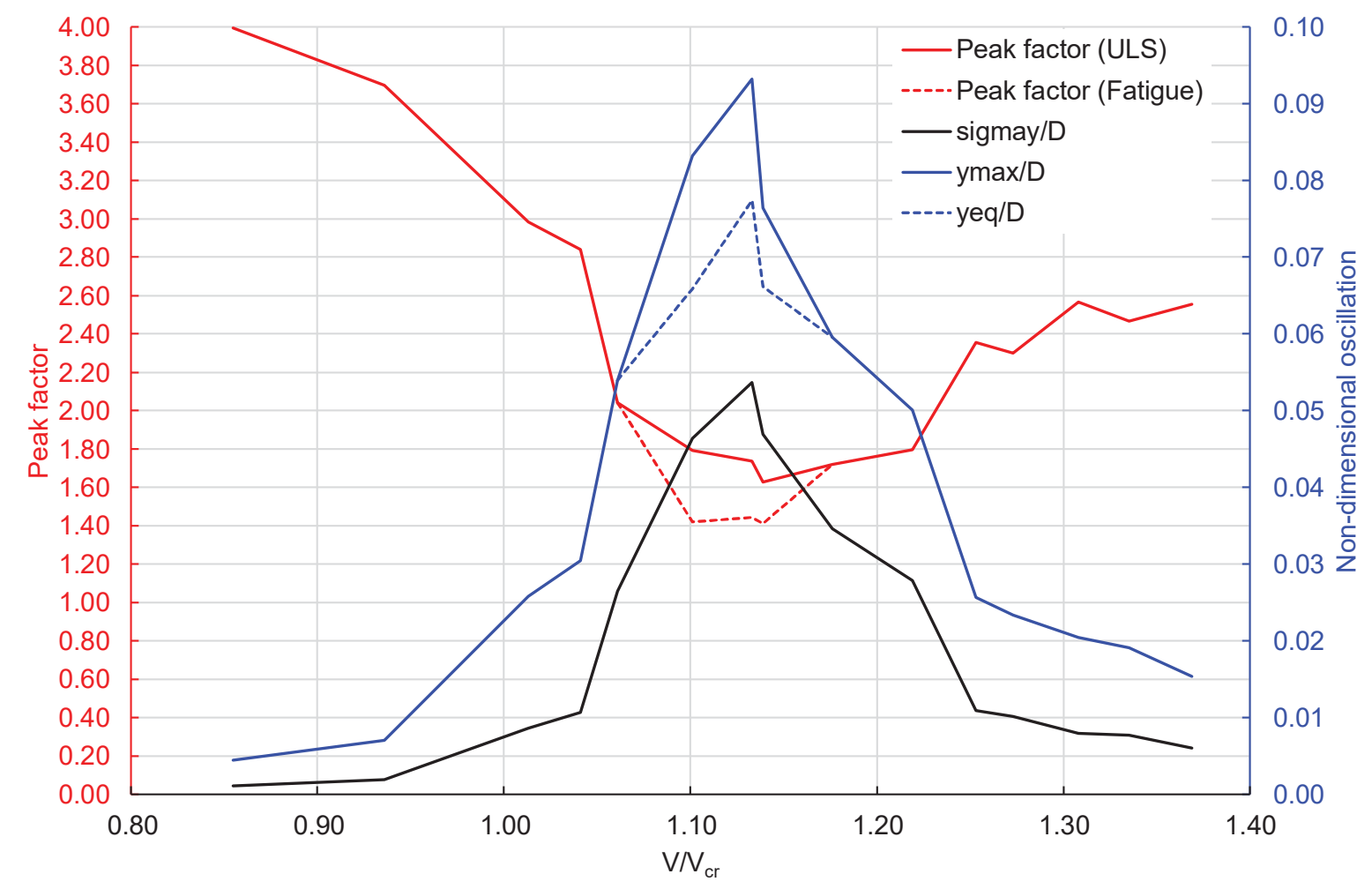

Figure 18: Peak factors for ultimate limit state (ULS) and equivalent peak factors in the lockin range for fatigue analysis

\begin{tabular}{|c|c|c|c|c|c|c|c|c|}
\hline $\begin{array}{l}\text { Veloc- } \\
\text { ity clas- } \\
\text { ses }\end{array}$ & $\begin{array}{l}\mathrm{V}_{\mathrm{i}} / \\
\mathrm{V}_{\mathrm{cr}}\end{array}$ & $\begin{array}{c}\mathrm{y}_{\max , \mathrm{i}} / \mathrm{D} \\
\text { (Figure } \\
12 \mathrm{a})\end{array}$ & $\begin{array}{c}\sigma_{, \mathrm{i}} / \mathrm{D} \\
\text { (Figure 12a) }\end{array}$ & $\begin{array}{c}\mathrm{k}_{\mathrm{pi}}=\mathrm{y}_{\max , \mathrm{i}} / \\
\sigma_{, \mathrm{i}} \\
\text { (Figure 12b) }\end{array}$ & $\begin{array}{l}\mathrm{D}_{\mathrm{d}}=\mathrm{Cumu}- \\
\text { lative dam- } \\
\text { age through } \\
\text { Rainflow }\end{array}$ & $\begin{array}{c}\Delta \sigma_{\text {eq,i }}= \\
\text { equivalent } \\
\text { stress range } \\
{\left[\mathrm{N} / \mathrm{mm}^{2}\right]}\end{array}$ & $\begin{array}{l}\mathrm{y}_{\text {eq, }, \mathrm{i}} / \mathrm{D}= \\
\text { equivalent } \\
\text { amplitude }\end{array}$ & $\begin{array}{l}\qquad \mathrm{k}_{\mathrm{pi}, \mathrm{eq}}= \\
\text { equivalent } \\
\text { peak factor } \\
\text { for fatigue } \\
\text { analysis }\end{array}$ \\
\hline 1 & 0.855 & 0.004 & 0.001 & 3.995 & 0.000 & $\leq 18.212$ & $\leq 0.061$ & $\mathrm{n} / \mathrm{a}$ \\
\hline 2 & 0.936 & 0.007 & 0.002 & 3.696 & 0.000 & $\leq 18.212$ & $\leq 0.061$ & $\mathrm{n} / \mathrm{a}$ \\
\hline 3 & 1.013 & 0.026 & 0.009 & 2.985 & 0.000 & $\leq 18.212$ & $\leq 0.061$ & $\mathrm{n} / \mathrm{a}$ \\
\hline 4 & 1.041 & 0.030 & 0.011 & 2.838 & 0.000 & $\leq 18.212$ & $\leq 0.061$ & $\mathrm{n} / \mathrm{a}$ \\
\hline 5 & 1.061 & 0.054 & 0.026 & 2.042 & 0.000 & $\leq 18.212$ & $\leq 0.061$ & $\mathrm{n} / \mathrm{a}$ \\
\hline 6 & 1.101 & 0.083 & 0.046 & 1.792 & 0.234 & 19.675 & 0.066 & 1.420 \\
\hline 7 & 1.133 & 0.093 & 0.054 & 1.737 & 0.279 & 23.123 & 0.077 & 1.444 \\
\hline 8 & 1.139 & 0.076 & 0.047 & 1.627 & 0.145 & 19.765 & 0.066 & 1.411 \\
\hline 9 & 1.176 & 0.060 & 0.035 & 1.720 & 0.000 & $\leq 18.212$ & $\leq 0.061$ & $\mathrm{n} / \mathrm{a}$ \\
\hline 10 & 1.219 & 0.050 & 0.028 & 1.795 & 0.000 & $\leq 18.212$ & $\leq 0.061$ & $\mathrm{n} / \mathrm{a}$ \\
\hline 11 & 1.253 & 0.026 & 0.011 & 2.357 & 0.000 & $\leq 18.212$ & $\leq 0.061$ & $\mathrm{n} / \mathrm{a}$ \\
\hline 12 & 1.273 & 0.023 & 0.010 & 2.300 & 0.000 & $\leq 18.212$ & $\leq 0.061$ & $\mathrm{n} / \mathrm{a}$ \\
\hline 13 & 1.308 & 0.020 & 0.008 & 2.566 & 0.000 & $\leq 18.212$ & $\leq 0.061$ & $\mathrm{n} / \mathrm{a}$ \\
\hline 14 & 1.335 & 0.019 & 0.008 & 2.466 & 0.000 & $\leq 18.212$ & $\leq 0.061$ & $\mathrm{n} / \mathrm{a}$ \\
\hline 15 & 1.369 & 0.015 & 0.006 & 2.554 & 0.000 & $\leq 18.212$ & $\leq 0.061$ & $\mathrm{n} / \mathrm{a}$ \\
\hline Sum & & & & & 0.659 & & & \\
\hline
\end{tabular}

Table 5: Equivalent peak factors for fatigue analysis 


\section{CONCLUSIONS}

The paper analyzes the negative aerodynamic damping in vortex-induced vibrations through free-vibration tests on an aeroelastic model. The result is compared with the curve previously gained by the authors through forced-vibration tests and shows a good agreement. Then, fatigue analysis through rainflow cycle counting is applied to the time histories measured in the wind tunnel experiments, which show a quasi-periodic behavior in the lock-in range. In view of fatigue, not the maxima, but rather the stress distribution needs to be considered for the evaluation of the fatigue lifetime. The rainflow analysis allows the calculation of equivalent stresses which produce the same cumulative damage as the actual time histories with varying amplitude. In this way, a peak factor for fatigue analysis can be defined. Similarly, using the ultimate limit state peak factor that is applied to the standard deviation of the response, the largest oscillation in the lock-in range is calculated.

\section{ACKNOWLEDGEMENTS}

This work is part of a research project funded by the Deutsche Forschungsgemeinschaft (DFG, German Research Foundation) - Project number 426322127. The support is gratefully acknowledged.

\section{REFERENCES}

[1] ASTM E1049-85 Standard Practices for Cycle Counting in Fatigue Analysis, ASTM International. 2017

[2] CICIND Model Code for Steel Chimneys, The CICIND Chimney Standard, 2010.

[3] Dyrbye C., Hansen S.O., Wind Loads on Structures, John Wiley \& Sons Ltd, 1997.

[4] Ehsan F., Scanlan R.H. Vortex-Induced Vibrations of Flexible Bridges. Journal of Engineering Mechanics, Vol. 116, No 6, 1990.

[5] EN 1991-1-4. Eurocode 1: Actions on Structures, Part 1-4: General actions - Wind actions, 2010.

[6] DIN EN 1991-1-4/NA German National Annex to Eurocode 1. Actions on Structures, Part 1-4: General actions - Wind actions, 2010.

[7] EN 1993-1-9: Eurocode 3: Design of Steel Structures - Part 1-9: Fatigue, 2005.

[8] Frandsen S., RISO kontraktrapport: Tvaersvingninger af stalskorstene. Feltmalinger. Roskilde (in Danish), 1979.

[9] Lupi F., Niemann H.-J., Höffer R., A novel spectral method for cross-wind vibrations: Application to 27 full-scale chimneys. Journal of Wind Engineering and Industrial Aerodynamics, 171, pp. 353-365, 2017.

[10] Lupi F., Niemann H.-J., Höffer R., Aerodynamic damping model in vortex-induced vibrations for wind engineering applications. Journal of Wind Engineering and Industrial Aerodynamics, 174, pp. 281-295, 2018.

[11] Náprstek J., Fischer C. Analysis of the quasiperiodic response of a generalized van der Pol nonlinear system in the resonance zone. Computers and Structures, 207, pp. 59-74, 2018. 
[12] Ruscheweyh H.; Sedlacek G., 1988. Crosswind vibrations of steel stacks. - critical comparison between some recently proposed codes. Journal of Wind Engineering and Industrial Aerodynamics, Volume 30, Issues 1-3, 173-183.

[13] Ruscheweyh H., Ein verfeinertes, praxisnahes Berechnungsverfahren wirbelerregter Schwingungen von schlanken Baukonstruktionen im Wind. Beiträge zur Anwendung der Aeroelastik im Bauwesen, Heft 20. Innsbruck Lausanne, 1986

[14] Vickery B.J., Basu R.I., Across-wind Vibrations of Structures of Circular Cross-section. Part I: Development of a mathematical model for two-dimensional conditions. Journal of Wind Engineering and Industrial Aerodynamics, Vol. 12, 49-73, 1983. 